\title{
Indivíduos, sociedade, tecnologia: as manifestações nas ruas das cidades brasileiras e as redes sociais
}

\author{
Individuals, society, technology: manifest in the streets of Brazilian cities and social \\ networks
}

\author{
Alexandre Ramos ${ }^{38}$ \\ Régia Oliveira ${ }^{39}$
}

Artigo recebido para publicação em Out./2013 e aceito para publicação em Ago./2014.

\section{RESUMO}

A sequência de manifestações ocorridas na cidade de São Paulo, que tiveram como elemento motivador primeiro o aumento das tarifas do transporte público em $R \$ 0,20$ (vinte centavos de Real), no dia 02 de junho de 2013, levou milhares de pessoas às principais avenidas da referida cidade em protesto contra o aumento. De maneira rápida, os protestos liderados pelo Movimento Passe Livre, cerca de sete ao todo, obtiveram amplo apoio de jovens estudantes e da opinião pública. $\mathrm{O}$ texto tem como objetivo analisar a relação entre tecnologia e sociedade a partir da busca de compreensão da articulação entre redes sociais e adesão às manifestações nas ruas. Busca-se discutir os sentidos das participações nas manifestações à luz da compreensão dos conceitos de identidade, identificação, em um contexto de massa. $O$ texto faz parte de pesquisa em desenvolvimento que discute os "novos" sentidos de interação social tendo em vista a crescente informatização das relações sociais, no momento contemporâneo.

Palavras-chave: Redes sociais. Facebook. Manifestações sociais. Identidade. Identificação.

\section{ABSTRACT}

The sequence of events occurring in São Paulo city, which had as first motivator the increase of the public transport fares in $R \$ 0,20$ (twenty cents of Real, something about U.S.\$0,10), on June 2, 2013, led thousands of people to the main avenues of the city to protest against it. Quickly, the protests led by the Free Pass Movement (FPM), about seven in all, had wide support of young students and the public. The text aims to analyze the relationship between technology and society from the pursuit of understanding the relationship between social networks and the act the people to join the street demonstrations. The article discusses the meanings of participation in those events based in the understanding of the concepts of identity and identification in a context of mass. The text is part of developing research that discusses the "new" way of social interaction in view of the growing computerization of social relations in the contemporary moment.

Keywords: Facebook. Social networking. Social events. Identity. Identification.

${ }^{38}$ Mestrando em Estudos Culturais pela Escola de Artes, Ciências e Humanidades, EACH- USP; Professor de Sociologia no ensino médio; área de interesse: Sociologia, Tecnologia de Informação. Instituição de Vinculação: Universidade de São Paulo/Escola de Artes, Ciências e Humanidades (USP/EACH).E-mail: alexandresociologia@usp.br.

39 Doutora em Sociologia; Professora Doutora da Escola de Artes, Ciências e Humanidades e do Programa de Pós Graduação em Estudos Culturais, EACH- USP; área de interesse: Sociologia; Antropologia. Instituição de Vinculação: Universidade de São Paulo/Escola de Artes, Ciências e Humanidades (USP/EACH). E-mail: re.oliveira@usp.br. 


\section{INTRODUÇÃO}

O presente artigo objetiva discutir uma das formas de expressão da relação entre tecnologia e sociedade, no momento contemporâneo, mais precisamente, o processo de interação, participação política e comunicação entre indivíduos, por meio das redes sociais facebook. A partir da apreensão de informações veiculadas sobre as manifestações ocorridas na cidade de São Paulo, lideradas pelo Movimento Passe Livre (MPL) e que tiveram como motivador central o aumento da tarifa do transporte público da cidade de $R \$ 3,00$ para $R \$ 3,20$, pretende-se discutir essa relação, buscando-se os sentidos das participações nas manifestações à luz da compreensão dos conceitos de identidade, identificação, em um contexto de massa. O texto faz parte de pesquisa em desenvolvimento que discute os "novos" sentidos de interação social tendo em vista a crescente informatização das relações sociais, no momento contemporâneo.

\section{A "REVOLTA DO VINAGRE" E O REDIMENSIONAMENTO DO ESPAÇO URBANO}

Como descreve Mayol (2011, p. 38), um dos registros de articulação da vida cotidiana é dado pelos "comportamentos, cujo sistema se torna visível no espaço social da rua", traduzindo-se "pelo vestuário, pela aplicação mais ou menos estrita dos códigos de cortesia [...], o ritmo de andar, o modo como se evita ou ao contrário se valoriza este ou aquele espaço público". Precisamente este último elemento, a valorização do espaço público, deve ser ressaltada na discussão sobre as manifestações nas ruas de São Paulo, lideradas pelo Movimento Passe Livre (MPL).

As manifestações expressaram o acirramento do redimensionamento do espaço urbano, no sentido do valor agregado à sua utilização: um espaço ocupado para a manifestação de diferentes vozes, reivindicações e interesses organizados por meio de redes sociais, instrumento tecnológico fundamental na divulgação e participação dos indivíduos.

Durante as manifestações lideradas pelo Movimento Passe Livre (MPL), ocorridas em São Paulo e em outras cidades brasileiras, foi possível perceber um aumento crescente de pessoas a cada novo ato desse Movimento. Das 2.000 pessoas que estavam envolvidas na primeira manifestação no dia 06 de junho de 
2013, passou-se para 100.000 pessoas na sétima manifestação, esta última organizada para o dia 20 de junho, antes da revogação do aumento das tarifas, mas, mantida mesmo após o anúncio da redução da tarifa, no dia 19 de junho, ao valor original $(R \$ 3,00)^{40}$.

Ao mesmo tempo, os protestos espalhavam-se por várias capitais de todo 0 país e em outras cidades, inclusive em locais onde o MPL não possuía representantes. Milhares de pessoas foram às ruas protestar, por diversos motivos, muitos deles relacionados aos fatos atuais da política nacional, mas que, em geral, revelava uma insatisfação em relação à situação atual do país.

A coexistência de diferentes grupos nas manifestações, revela-nos, por um lado, a inteligibilidade das redes sociais como meio de comunicação entre os indivíduos, sinalizando a importância desse veículo na sociabilidade contemporânea e, por outro, o hibridismo que a caracteriza, tendo em vista a participação dos indivíduos em diferentes grupos. A esse respeito, Canclini (2008), a partir de uma perspectiva pluralista, destaca, no estudo das sociedades latino americanas, como o Brasil, as múltiplas tradições e a coexistência do moderno com o tradicional, como podem expressar as inovações tecnológicas convivendo com cultos populares.

No caso das manifestações, sua divulgação e ampliação do número de participantes e adesões evidencia a relevância das redes sociais, especialmente em função da facilidade e rapidez de transmissão das informações e da comunicação. O acompanhamento dos fatos através das redes sociais da internet, entre elas o Facebook e o Twitter, resultou na adesão cada vez maior ao movimento ${ }^{41}$.

Pensar o papel das redes sociais nesses episódios é fundamental, diante de uma cobertura muitas vezes enviesada dos meios de comunicação que denomina como notícia os fatos que ela seleciona para chegar aos telespectadores ou ouvintes. Segundo Milton Santos, fábulas e/ou mitos são construídos, isso porque as mídias nacionais se globalizam, criando uma interpretação que corresponde aos interesses de mercado (SANTOS, 2004, p. 40).

${ }^{40}$ Dados obtidos no Portal G1 de informações. Link: http://migre.me/kGls6. Acesso em: 22 de Jun. 2013. Sobre o retrospecto das manifestações em São Paulo e no resto do país, conferir a linha do tempo disponível nesse Portal.

${ }^{41}$ A informação foi obtida pelo site Scup. No dia 14 de junho, este site criou um monitoramento nas mídias sociais para acompanhar a repercussão dos protestos que estavam acontecendo nas ruas. Foram coletadas mais de dois milhões de menções aos protestos entre os dias 13 e 21 de junho, em plataformas como YouTube, Google News, Twitter e Facebook. Nesse período, mais de 900.000 usuários deixaram comentários sobre o tema. Os dados completos podem ser acessados no link http://ideas.scup.com/pt/especiais/a-semana-em-protestos-dados-das-midias-sociais/. Acessado em: 23 de Jun. de 2013. 
Nesse contexto, as redes sociais gozam de certa independência e agilidade na transmissão dos fatos. Em minutos, milhares de informações textuais, vídeos, áudios, imagens, permitem às pessoas uma independência em relação aos veículos tradicionais. A combinação de ambos, nos casos acima, demonstrou a assimetria entre mídia tradicional e as redes sociais, como argumenta Manili (2013).

\section{OS MANIFESTANTES E A IDENTIDADE NACIONAL EM QUESTÃO}

"Sou brasileiro, com muito orgulho, com muito amor..."

Segundo Hall (1992, p. 67), a globalização pode ser entendida como os processos "atuantes numa escala global que atravessam fronteiras nacionais, integrando e conectando comunidades e organizações em novas combinações de espaço-tempo, tornando 0 mundo, em realidade e em experiência, mais interconectado".

Nesse contexto, discute-se a existência de uma crise de "identidade nacional". Para Canclini (2008), o modelo político tradicional dos países modernos está em declínio. Uma das expressões disso é a expansão do neo-liberalismo que acaba por minar o papel do Estado. Para o autor, esse contexto caracteriza-se pelas grandes mobilidades e fragmentações em diversas ordens da vida. Há uma reelaboração em torno de uma economia globalizada, da qual faz parte a redefinição da identidade e do pertencimento que ultrapassam fronteiras específicas.

As manifestações nas ruas da cidade expressaram diversos interesses e reivindicações, dentre os quais, a "luta" pela "igualdade"; contra as ditaduras; por causas ambientais, pelo fim da miséria e da fome; pelo acesso à educação de qualidade; pela melhoria do sistema de saúde, entre os outros temas, que acabam por acolher diferentes identidades e identificações.

Como desenvolve Canclini (2008), hoje em dia, as identidades configuram-se de uma forma mais móvel. O que há são processos em construção que configuram diferentes identidades. $O$ indivíduo tem múltiplas identidades. Isso faz acentuar as diferenças étnicas, de gênero etc.

O pertencimento a uma classe ou a uma nação é apenas uma referência que tem sentido em determinados momentos. Ser brasileiro é uma construção social e as construções sociais tem se tornado cada vez mais plásticas e voláteis (idem). 
Para Hall (2006), dada a globalização, o mundo social e cultural encontra-se descentrado; fragmentado, fazendo com que a noção de identidade nacional contraponha-se à ideia de identidade partilhada. Essa situação coloca o sujeito numa trama complexa, uma vez que o insere numa cultura nacional, que possui seus aspectos e ordenamentos particulares ligados a um determinado espaço e, ao mesmo tempo, o relaciona ao mundo global e às suas influências. É o que o autor chama de descentramento.

Nas manifestações aqui discutidas, a construção da ideia do "ser brasileiro" e de sua plasticidade (CANCLINI, 2008), fizeram-se em meio à multiplicidade de identidades e identificações, estas expressas nos diferentes temas que mobilizaram os manifestantes, fazendo ampliar o contato, via internet, dos grupos afins e da circulação de informações.

Esse aparato tecnológico colocou em evidência um certo tipo de interação entre os indivíduos e de expressão das diferentes identidades e identificações no espaço das ruas, a partir das manifestações. Tratou-se, inicialmente, de uma interação "virtual", ou, nos termos de Le Breton (2003), "sem rosto e sem corpo".

Por meio da internet, em especial, do facebook, os indivíduos puderam se encontrar virtualmente, trocar informações, marcar encontros de participação nas manifestações das ruas. Nesse momento, dos encontros virtuais, os limites impostos pelas fronteiras do espaço e do tempo deixam de ser um problema, possibilitando o intercâmbio entre diferentes pessoas (LE BRETON, 2003).

Como discute o autor, no momento contemporâneo, por meio da internet, aquele indivíduo que está longe, torna-se próximo, enquanto aqueles que estão próximos, ocupam um espaço reservado dentro das relações sociais. Para Le Breton (2003, p. 144), o espaço da internet, "cibernético", dos encontros nos chats, representa "um mundo em que o tempo, liberado da duração, converte-se em espaço de puras informações que não requerem mais a corporeidade humana".

Nas manifestações das ruas aqui discutidas, o requerimento da "corporeidade", da presença física dos indivíduos para expressão de suas reivindicações foi intercalado por encontros virtuais que aproximaram as pessoas segundo diferentes identificações.

Todavia, as identificações a determinadas causas defendidas nas manifestações também marcaram diferenças e conflitos. Em uma entrevista para o jornal Le Monde, o antropólogo francês Lévi-Strauss usa o termo "compenetração mútua" para se referir à civilização em escala mundial. O autor destaca a existência 
de diferenças não apenas externas, mas também internas. Segundo o autor, essas diferenças passam a se intensificar em um contexto cada vez mais marcado por essa multiplicidade que convive, mas que não coexiste. Uma convivência marcada por conflitos.

Para Porto Gonçalves (2002, p.229-230), as análises sobre a globalização levam em consideração a questão do tempo histórico, mas poucas são aquelas que consideram a "geograficidade da história", onde os sujeitos se apropriam do espaço (territorialização), conferindo-Ihe um sentido (territorialidades).

No referente às manifestações aqui discutidas, na (re)apropriação do espaço, ao longo das duas semanas e das sete manifestações que se seguiram, incluindo as diversas manifestações que se espalharam pelo Brasil afora, a mensagem que se propagava era: “Não é pelos $R \$ 0,20$ ”, em alusão ao aumento da passagem, mas, dentre outros fatores, pela corrupção, pela falta de transparência política, pela falta de investimento em educação, pelo descaso na saúde, pela falta de segurança, pelos impostos abusivos, por críticas à atuação do poder executivo.

Diferente dos movimentos antiglobalização que, por meio das redes sociais, formavam-se para discutir questões globais, agora a população brasileira se "unia" para discutir questões internas, portanto, ligadas ao reconhecimento de uma "identidade nacional", nesse caso, a de "brasileiro". Uma identidade construída de modo fluida (CANCLINI, 2008), em torno de diferentes reivindicações, que acentuavam, em momentos diferentes, um ou outro aspecto do "ser" brasileiro. Como destaca Monteiro (1996), esse sentimento de "ser" brasileiro pode ser mais "imaginado" nesses grupos que se organizam em torno de lutas civis, por interesses comuns. De todo modo, destaca a autora, é preciso indagar se aquilo que une as pessoas nessas lutas, e que as identifica, não é a situação de desprovidos de direitos, de oprimidos. No caso das manifestações das ruas, as reivindicações por diferentes direitos - como à tarifa reduzida de transporte público; à educação e saúde -, expressam o reconhecimento da necessidade de superação de desigualdades sociais do cidadão brasileiro.

No referente à noção de espaço para pensar as possibilidades de uma "identidade nacional" no mundo globalizado, Massey (2008, p. 24-29) discute a necessidade de uma "abordagem alternativa" reconhecendo o espaço como "produto de inter-relações" que abrange desde a "imensidão global até o intimamente pequeno". Para o autor, é preciso considerar que a globalização não elimina as características fundamentais do Estado nacional que confere a identidade 
nacional, assim como pensar o espaço nessa perspectiva possibilita apreender as "trajetórias múltiplas", os conflitos e os sujeitos dentro do Estado nação, pensado como "esfera do cotidiano, de práticas reais e valorizadas, a fonte geográfica de significado".

Gonçalves (2002, p. 220), aponta outro aspecto importante do mundo globalizado que pode aqui ser repensado para a discussão das manifestações das ruas e, com ela, do surgimento das diferenças e das recriações do espaço público. Segundo afirma, "esses sujeitos que muitos chamam de novos, embora não o sejam tanto, põem em debate outras questões, outras relações [...] e, mais do que resistir, r-existiram, reinventaram-se na sua diferença, assim como o europeu é, também, uma invenção na diferença, embora na condição de pólo dominante no 'sistemamundo'.

\section{AS REDES SOCIAIS E A FORMAÇÃO DA MASSA}

"Saímos do Facebook", revelavam alguns cartazes nas ruas.

A maneira "repentina" como o povo "resolveu" sair às ruas para se manifestar, envolve uma complexidade que impossibilita enxergar a situação por um único caminho.

Fato é que, mesmo os organizadores do MPL certamente não esperavam tamanha repercussão. Em muitas localidades, os protestos ocorriam por "formação espontânea", tendo sempre como meio as redes sociais. Em pouco tempo, grupos começaram a agendar suas manifestações, em diversos bairros.

$\mathrm{Na}$ figura 1 temos um gráfico gerado pelo site Causa Brasil ${ }^{42}$, a partir dos assuntos mais comentados entre os dias 16 e 17 de junho. Os termos foram divididos em subáreas como: direitos básicos (laranja); economia (vermelho); liberdades individuais (azul); copa do Brasil (verde); e, políticos (roxo).

O "preço das passagens" com 27,66\% (direitos básicos); seguido de "democracia", com 15,43\% (liberdades individuais); e, "postura política" com 9,15\% (liberdades individuais).

\footnotetext{
${ }^{42} \mathrm{O}$ site gera gráficos a partir dos itens mais procurados na internet, através de sites como Facebook, Google, Twitter, Instagram e YouTube. Link: http://www.causabrasil.com.br/. Acesso em: 22 de Jun. 2013.
} 


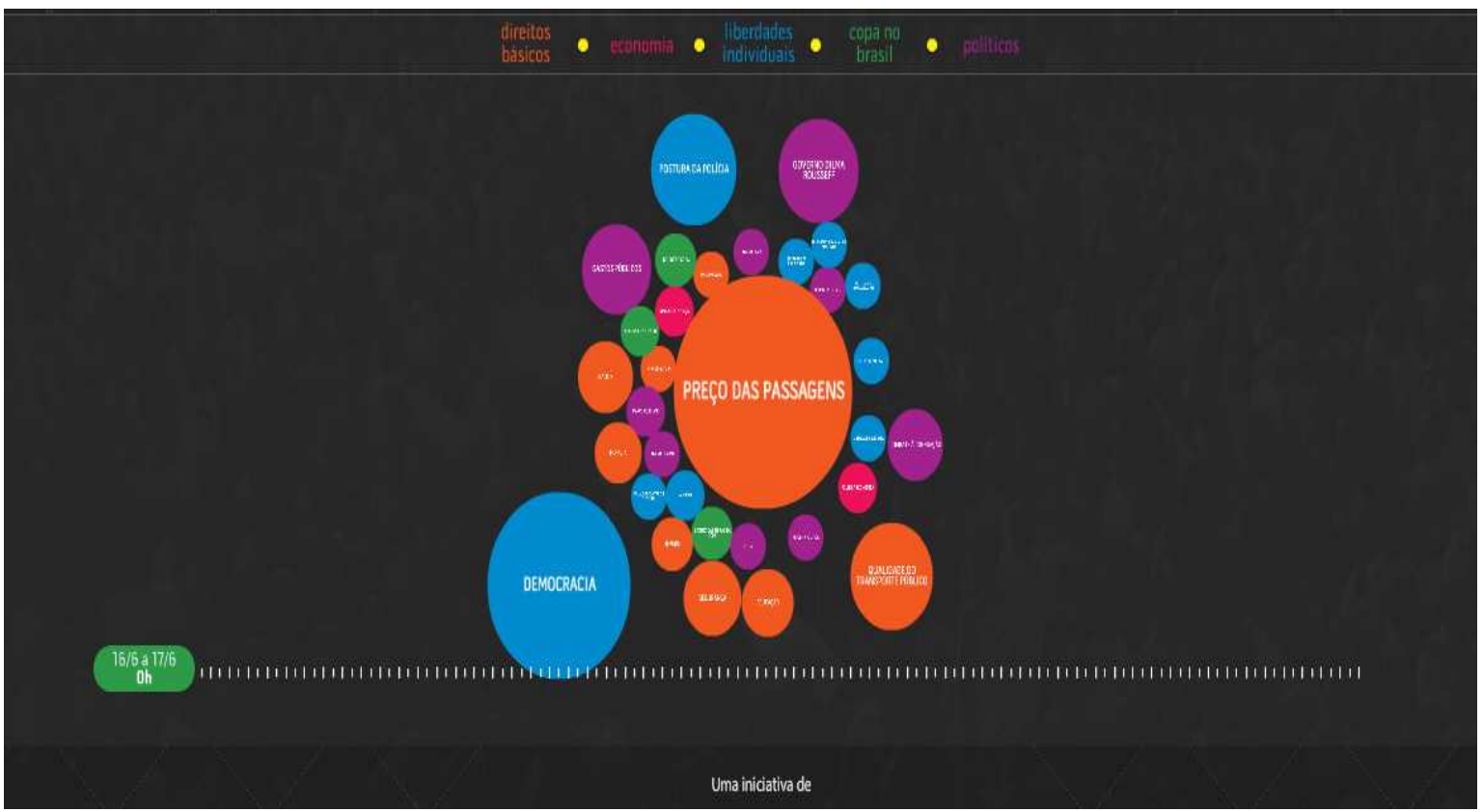

$\mathrm{Na}$ figura 2, há um gráfico com os assuntos mais comentados nas redes sociais, entre os dias 19 e 20 de junho. Os temas mencionados se ampliam, incluindo questões mais gerais como "qualidade do transporte público", "segurança", "saúde", "combate à corrupção" e "governo Dilma Roussef". Todos esses assuntos alcançando entre $6.5 \%$ e $9.98 \%$ das menções através das redes sociais. Resumindo, a questão dos transportes ficou em segundo plano, dando espaço para outros temas de insatisfação dos internautas.

Figura 2

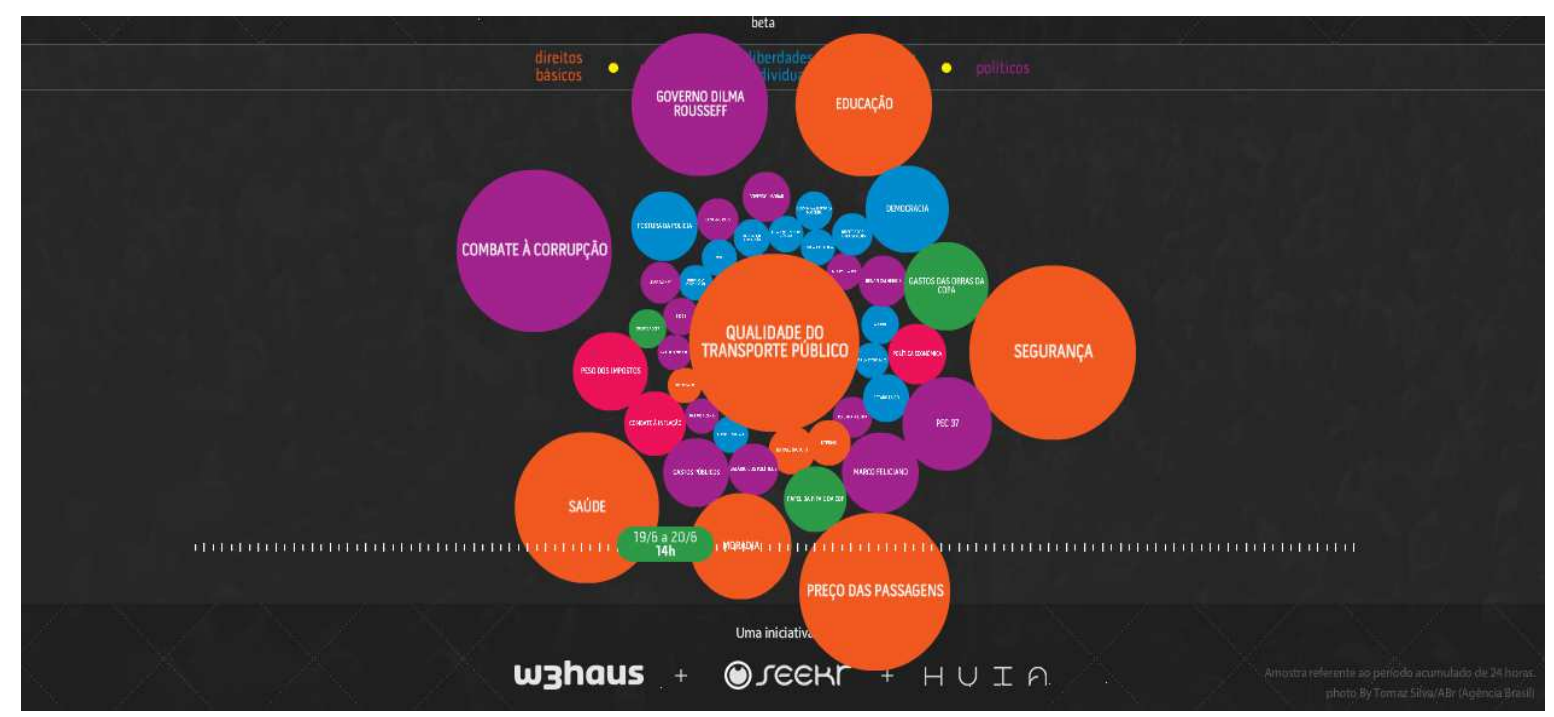

Outros dados possibilitam confirmar uma diversidade de reivindicações que povoou as manifestações, entre dos dias 06 a 21 de junho. Os gráficos da imagem 3 
são do Instituto Datafolha ${ }^{43}$, e se referem a uma pesquisa realizada com 606 moradores da cidade de São Paulo, no dia 21, após o anúncio da redução da tarifa. $\mathrm{O}$ apoio às manifestações é demonstrado por $66 \%$ das pessoas entrevistadas.

Ao perguntar sobre os assuntos, o resultado da pesquisa revela uma consonância com os dados apresentados pelo site Causa Brasil. Novamente, temos uma série de assuntos sendo colocados em pauta que ultrapassam a questão dos transportes. Saúde, educação, corrupção e segurança pública aparecem entre os assuntos mencionados pelos entrevistados.

Além da diversidade de temas e interesses em torno das manifestações, os dados evidenciam a participação daqueles que as acompanham, também demonstrando a legitimidade dessas participações pela maior parte da população, ao mesmo tempo em que revela "novas" sociabilidades em torno e por meio das redes sociais.

Nas ruas, diversos grupos apresentavam-se em cena: jovens com máscaras de Guy Fawkes, registrando o que acontecia em seus celulares e tablets; senhores e senhoras de meia idade, cobrando por melhorias nos serviços públicos; skinheads, punks, bikers e manos; todos "reunidos" e "separados", compondo uma massa.

Num sentido psicanalítico, como explicita Freud (1921, p. 20), a massa referese ao desenvolvimento da "superestrutura psíquica" dos indivíduos de maneira diversa, que se desmontando, permitindo que os "fundamentos do inconsciente comum a todos" sejam postos a nu. Na massa, nessa perspectiva, o sujeito permitese o anonimato, liberando impulsos e instintos, que em situações cotidianas não seriam demonstradas. Há aí o fortalecimento de impulsos, guiados exclusivamente pelo inconsciente (FREUD, 1921, p. 25).

Pode-se levantar a ideia de que a identificação que proporcionou a adesão dos indivíduos ao movimento corresponde, como define Freud, "às ligações afetivas dos sujeitos em relação ao objeto desejado, por estabelecer uma ligação comum com este objeto" (FREUD, 1921, p. 65).

O problema que se coloca é o fato de a "massa" caracteriza-se por um todo amorfo e descontrolado, onde essas identificações podem se formar a partir de motivações individualistas, resultando no que Freud (2011, p. 19) denominou de "a miséria psicológica das massas". Como diz o autor, tal "perigo ameaça, sobretudo quando a ligação social é estabelecida principalmente pela identificação dos

\footnotetext{
${ }^{43}$ Informações disponíveis em: http://migre.me/fgscE. Acesso em: 23 Jun. 2013. 
membros entre si, e as individualidades que podem liderar não adquirem a importância que lhes deveria caber na formação da massa.

Numa perspectiva sociológica, a massificação implica indiferenciação. Como discute Simmel (1979, p. 18), é na cidade que é possível ser livre e igual e, ao mesmo tempo, cultivar a singularidade. Segundo o autor, uma das características da metrópole é que ela "confere ao indivíduo uma qualidade e quantidade de liberdade pessoal que não tem qualquer analogia sob outras condições” (SIMMEL, 1979, p. 18). Mas é também na cidade, avalia, que essa possibilidade é negada, pois para que cada um possa em tese desenvolver as qualidades únicas é necessário que sejamos iguais. Ao mesmo tempo, é na metrópole, pela ampliação do grupo de indivíduos que se dá a possibilidade da emergência do indivíduo particular que, ao mesmo tempo, "precisa enfrentar a dificuldade de afirmar sua própria personalidade no campo abrangido pelas dimensões da vida metropolitana" (SIMMEL, 1979, p. 22), do qual fazem parte e se fazem sentir mais fortemente pelo indivíduo na cidade, a "reserva e indiferença recíprocas". Coloca-se, portanto, um conflito inerente à vida nas grandes metrópoles que o estudo das manifestações nas cidades pode também revelar.

Outro aspecto refere-se às expressões de agressividade no interior das manifestações, de grupos e/ou de indivíduos ali presentes. Inicialmente, o coro "nós" pode se tornar em seguida a divisão entre "nós" e "eles" e, a partir disso, criar situações de ataque recíproco. Esse fator está ligado ao poder agregador das redes sociais no espaço virtual, porém, no isolamento de suas particularidades, esses mesmos grupos passam a ser imbuídos do que Freud (1929, p. 60) denominou como "narcisismo das pequenas diferenças", pois é possível que um sentimento de amor ligue os pequenos grupos, desde que, segundo o autor, "restem outras para que se exteriorize a agressividade".

Para Telles (2013), "os meios de comunicação tornam mais complexa essa equação", pois eles permitem a organização de "multidões virtuais muito maiores que as reais". A adesão de internautas a uma determinada manifestação não significa sua presença no local e na hora determinada do evento, mas, a confirmação ou não, exige dele um posicionamento.

Nas redes sociais, as informações são produzidas de forma extremamente rápida ou mesmo instantânea, em tempo real, conseguindo superar os meios tradicionais de mídia. Como descreve Recupero (2012), a disposição dos atores em replicar essas informações está diretamente ligada ao contexto de uma determinada 
realidade. Há um investimento nas relações, inclusive nos laços sociais fracos, pois este possibilitará aos indivíduos o acesso às informações, na qual ele irá acessar, selecionar e reproduzir conforme interesse específicos, transformando as redes sociais da internet não apenas em redes de comunicação, mas também em meios de difusão de informação e de "novas" sociabilidades.

\section{COMENTÁRIOS FINAIS}

Se, conforme avalia Recupero (2012), as informações transmitidas de modo instantâneo na internet são descentralizadas e constituídas por "laços sociais fracos", as recentes manifestações iniciadas em meio a reivindicações contra o aumento da tarifa, a partir das quais ramificaram-se outras demandas, parecem sinalizar a existência de uma dimensão para além da opacidade, em termos de "laço social, do espaço virtual, dizendo respeito a construções de novas sociabilidades e identificações que revelam importantes articulações entre indivíduo, sociedade e tecnologia.

Para Burges e Green (2009), as novas tecnologias de comunicação na internet possibilitam o desenvolvimento de uma "cultura participativa", porém, sem o controle de grupos de interesses específicos, afirmativa discutível.

O texto buscou destacar o papel que a redes sociais da internet tiveram na difusão de mensagens e informações no sentido de propiciar a formação de uma massa que saiu às ruas pelos mais diversos motivos. Muitos, contraditórios às reivindicações iniciais propostas pelo Movimento Passe Livre, no caso, a redução da tarifa de ônibus. Tratou-se de destacar, a partir da apreensão das manifestações, o modo como indivíduo, sociedade e tecnologia se articularam, expressando complexas e "novas" sociabilidades, identidades e identificações.

Importante destacar que a noção de identidade pressupõe alteridade. Não é possível pensar o indivíduo sem o conjunto ao qual ele pertence. Contemporaneamente, esse "conjunto" diversifica-se, assim como os processos de identificação e de participação social, a exemplo das redes sociais que mobilizam ações, opiniões e participações diversas, tornando ainda mais complexa a ideia de interação social e, mesmo, de vida social. 


\section{REFERÊNCIAS}

BURGES, J.;e GREEN, J. You Tube e a revolução digital: como o maior fenômeno da cultura participante transformou a mídia e a sociedade. São Paulo: ALEPH, 2009.

CANCLINI, N. G. Culturas híbridas: estratégias para entrar e sair da modernidade. 4. ed. São Paulo: EDUSP, 2008.

FREUD, S. Psicologia das massas e análise do eu (1921). In: FREUD, Sigmund. Obras Completas, v. 15 (1920-1923). São Paulo: Companhia das Letras, 2011.

FREUD, S.. O mal-estar na civilização (1929). São Paulo: Penguim Classics, 2011.

GONÇALVES, C W. P. Da geografia às geo-grafias: um mundo em busca de novas territorialidades. In: CECENÃ, Ana Esther; SADER, Emir (orgs). La Guerra Infinita: Hegemonía y terror mundial. Buenos Aires, CLACSO 2002.

HALL, S. A identidade cultural na pós-modernidade. Rio de Janeiro: DP\&A, 2006.

LE BRETON, D. Adeus ao corpo: antropologia e sociedade. Campinas/SP: Papirus, 2003.

LÉVI-STRAUSS, C. Longe do Brasil. Entrevista com Véronique Moraigne. São Paulo: Editora Unesp, 2011.

MALINI, F. A. B. Do Vinagre: por que o protesto SP não teve uma, mas muitas hashtags. Laboratório de estudos sobre Imagem e Cibercultura (LABIC), Universidade Federal do Espírito Santo. Disponível em: http://migre.me/f8DxC, Acesso em: 20 jun. 2013.

MASSEY, D. B. Pelo espaço: uma nova política da espacialidade. Rio de Janeiro: Bertrand Brasil, 2008.

MAYOL, P. Primeira parte. Morar. In: CERTEAU, M; GIARD, L; MAYOL, P. (org). A invenção do cotidiano 2. Morar, cozinhar. Petrópolis: Vozes, 2011. Pg 37-45.

MONTEIRO, P. Diversidade cultural: inclusão, exclusão e sincretismo In: DAYRELL, Juarez (org). Múltiplos olhares sobre educação e cultura. Belo Horizonte: ED. UFMG, 1996.

RECUERO, R. A rede é a mensagem: Efeitos da Difusão de Informações nos Sites de Rede Social. In: VIZER, Eduardo. (Org.). Lo que McLuhan no previó. Buenos Aires: Editorial La Crujía, 2012.

SIMMEL, G. A Metrópole e a Vida Mental. In: VELHO, Otávio Guilherme (org.). 0 Fenómeno Urbano. 4. ed.Rio de Janeiro: Zahar, 1979.

TELLES, S. Massas versus cidadania. Site Estadão: Abr/2013. Disponível em <http://migre.me/fcjfs>. Acesso em: 20 de Abr. 2013. 